\title{
From the Surface to the Depths: On the Transition from Logic of Sense to Anti-Oedipus
}

\author{
DANIEL W. SMITH, Purdue University
}

In his 2004 book Organs without Bodies: Deleuze and Consequences, Slavoj Žižek curtly dismisses Anti-Oedipus (1972) as "arguably Deleuze's worst book," and instead elevates Logic of Sense (1969) to the status of Deleuze's pivotal work. ${ }^{1}$ At the heart of Logic of Sense, Zižek claims, one finds a tension between two competing ontologies which are in turn derived from two competing conceptions of sense: sense as the impassive effect of material causes and sense as the principle of the cause or production of beings. ${ }^{2}$ The former would be the logic of materialism, the latter the logic of idealism. Žižek's argument is that the conceptual edifice of Deleuze's entire philosophy oscillates between these two "logics" of sense, which are in the end "fundamentally incompatible."13 According to Žižek, however, the tension between these two ontologies is a necessary one, since it points to the fact that any genuine "event" entails the emergence of something new that cannot simply be derived from corporeal causes, and which therefore has its own "incorporeal" effects. ${ }^{4}$ The problem with Anti-Oedipus, according to Žižek, is that it largely abandons the (Lacanian) presuppositions that govern Logic of Sense, and instead offers what Žižek takes to be the simplistic solution of a materialism of pure becoming. Anti-Oedipus was "the result of escaping the full confrontation of the deadlock via a simplified 'flat' solution," and the thrust of Žižek's reading of Deleuze in Organs without Bodies is "to confront again this deadlock" between the two ontologies (sense as effect and sense as cause) in order to retrieve the importance of Logic of Sense for an understanding of Deleuze's work. ${ }^{5}$

Žižek is certainly correct to see a shift in Deleuze's thought between Logic of Sense and Anti-Oedipus. The fact that such a shift exists is confirmed by Deleuze himself. "The surface-depth problem [of Logic of Sense] no longer concerns me," he remarked in a 1973 interview. "What interests me now are the relations between a full body, a body without organs, and flows that migrate. ${ }^{\prime \prime 6}$ Žižek is also correct to perceive that this shift-from the surface-depth problem to the problem of the body without organs-is intimately linked to Deleuze's relation to and rereading of Lacan. It is perhaps inevitable that, to a Lacanian like Žižek, Anti-Oedipus could only be read as a regressive book, as a move away from Lacan's insights, whereas for Deleuze himself Anti-Oedipus was obviously a step forward, an exploration of problems that were left in 
abeyance in Logic of Sense. What the following reflections attempt to lay out, in a tentative manner, are the internal problematics of Logic of Sense that led Deleuze to reformulate his own position in Anti-Oedipus. After laying these out, we will be in position to assess the relevance of Žižek's rather curt dismissal of Anti-Oedipus.

In the second half of Logic of Sense, Deleuze attempts to analyze what he calls the dynamic genesis of language, drawing in part on texts from developmental psychology and psychoanalysis. "What renders language possible," he writes, "is that which separates sounds from bodies and organizes them into propositions, freeing them for the expressive function" (LS, 181). If a speaker before me suddenly relapsed into violent babbling and began to utter incomprehensible noises, one could say that the "expressive function" of sound would have been lost, or at least fundamentally altered. This is the issue addressed by the dynamic genesis of language: it "concerns the procedure that liberates sounds and makes them independent of bodies" (LS, 186). Deleuze distinguishes three different stages in the dynamic genesis, which at the same time constitute three distinguishable dimensions of language: the primary order of language, which is the dimension of noise produced in the depths of the body; the tertiary arrangement of language, which is found in the propositions of languages and their various functions of denotation, manifestation, and signification; and finally the secondary organization of language, which constitutes the surface of sense (and non-sense). The dimension of sense is the primary object of Deleuze's analyses in the Logic of Sense, since it conditions the movement from the primary order to the tertiary arrangement of language. I want to begin by briefly considering each of these three stages.

1. The Primary Order of Language. The dynamic genesis begins in the dimension of depth, which constitutes what Deleuze calls the primary order of language. The paradigmatic example here is the newborn infant, and the clamorous, noisy depth of its body, with its gnashings, fartings, clappings, crackings, explosions, and cries. This dimension of Noise constitutes a first type of non-sense and a first type of sonorous system. At this level of the body, "everything is passion and action, everything is communication of bodies in depth, attack and defense" (LS, 192). Daniel Stern, one of the great specialists in child development, describes the world of the infant as a kind of human "weatherscape" made up entirely of sequences of risings and fallings of intensity-the jolting of a bright light or a sharp noise, the calming of a voice, or the explosive breakout of a storm of hunger, with its knot of agony and screams, and then the passing of the storm when the baby is fed, and the subsequent sense of pleasure and satisfaction. ${ }^{7}$ This is what Deleuze calls the "body without 
organs": a situation where the infant experiences no distinction between itself and the world, but only intensities-in-motion, with "an entire geography and geometry of living dimensions" (LS, 188).

2. The Tertiary Arrangement of Language (Denotation, Manifestation, Signification). The second stage of the dynamic genesis then intervenes: in the midst of this world of intensities there appears a particular noise, a transcendent Voice from on high, so to speak-the voices of the child's parents, or those of other adults. Long before the infant can understand words and sentences, it grasps language as something that pre-exists itself, as something always already there: the familial voice that conveys tradition, or that affects the child as the bearer of a name. As opposed to the primary order of language (pure noise as the dimension of the body), the voice participates in what Deleuze calls the tertiary arrangement of language ("langue," a fully formed language) which is made of up sentences or propositions.

In the important "Third Series" of Logic of Sense Deleuze identifies three dimensions of propositions that make up the tertiary arrangement of language: (1) designation or denotation, which is the relation of a proposition to an external state of affairs (theory of "reference"); (2) manifestation, which marks the relation of the proposition to the beliefs and desires of the person who is speaking; and (3) signification or demonstration, which is the relation of the proposition to other propositions (the domain of logic, with its relation of implication or demonstration between propositions). In other words, in a language, propositions can be related either to the objects to which they refer or to the subjects who utter them, or to each other. Each of these dimensions of the proposition identified by Deleuze can be said to be grounded in a specific Kantian principle: the World, and its states of affairs, is the principle of reference or denotation; the Subject is the principle of manifestation; and God, as the locus of abstract predicates, is the principle of demonstration. These are the three transcendent Ideas that Kant identified as the three great terminal points of metaphysics in the "Transcendental Dialectic" of the Critique of Pure Reason: the Self, the World, and God. (If God is the principle of demonstration it is because Kant defines God as the master of the disjunctive syllogism: God is the ens realissimum, the sum total of all possibility, and the "reality" of each thing is derived from this originary material through the enactment of disjunctive [either-or] syllogisms. See LS, 176, 296.) Deleuze is here following Nietzsche (and others) in suggesting that traditional metaphysics is derived from (and led into "transcendent illusions" by) language and its grammar, that is, from the most general structure of propositions. 
The limitation of much philosophy of language is not only that it has tended to focus primarily on the relation of denotation or reference, that is, on the way in which propositions can designate a state of affairs, which determines the truth value of a proposition. The deeper problem is that it has tended to focus on propositions in fully formed and already developed languages - that is, on the tertiary arrangement of languagewithout posing the question of their genetic conditions. In biology, for instance, one does not discover the nature of the organism by simply examining a fully formed individual, since the individual itself is the result or effect of a complex set of processes, starting with the genetic code and passing through a series of developmental processes. The same is true of language: one is led astray if one analyzes language in its full blown, adult state, so to speak, without adopting a genetic point of view-although ultimately this genetic standpoint is a static standpoint, and not a developmental one. (As we shall see, Deleuze distinguishes between the dynamic genesis, which we are here discussing, and the formal, transcendental, or static genesis of the event). What then is this genetic element of language?

3. The Secondary Organization of Language (Sense and Nonsense). This question brings us to the third stage of the dynamic genesis, the third element of language, which lies "between" the primary order of language (pure noise) and its tertiary arrangement (in propositions). This is what Deleuze calls the secondary organization of language, which is the domain of sense. Why is sense the genetic element of language? Deleuze is here indebted to the genius of thinkers like Frege and Russell, who discovered that the condition of truth (or denotation) lies in the domain of sense: in order for a proposition to be true it must have a sense. Yet Frege and Russell betrayed this thesis at the moment they discovered it, Deleuze argues, because they fell into the circularity of the method of conditioning. One of Deleuze's essential theses in both Difference and Repetition and Logic of Sense was that, in transcendental philosophy, the Kantian method of conditioning (which elucidates the conditions of possible experience) must be replaced by a method of genesis (which elucidates the conditions of real experience). In Frege and Russell, sense is defined as the condition of the true, but it is granted an extension larger than truth in order to account for the possibility of error. A false or erroneous proposition nonetheless remains a proposition endowed with sense, whereas a proposition that does not have a sense can neither be true nor false; it is simply nonsensical. For instance, the famous opening line of Lewis Carroll's Jabberwocky ('Twas brillig, and the slithy toves did gyre and gimble in the wabe) is neither true nor false, but lacks sense. But in this manner, although the sense- 
nonsense relation is deemed to be prior to the truth-falsity relation, sense only grounds the truth of a proposition by remaining indifferent to what it grounds; the values of truth and falsity are allowed to continue in the same state as before, as if they were independent of the condition assigned to them (truth is still a matter of adequation or reference).

This then is what Deleuze calls "the most general problem of a logic of sense": "What would be the purpose of rising from the domain of truth to the domain of sense, if it were only to find between sense and nonsense a relation analogous to that of the true and the false?" (LS, 68). Deleuze thus alters the formulation of the problem of truth in terms of the problem of genesis: "Truth and falsity do not concern a simple designation, rendered possible by a sense which remains indifferent to it. The relation between a proposition and what it designates must be established within sense itself. the nature of ideal sense is to point beyond itself towards the object designated. ${ }^{18}$ Rather than utilizing a method of conditioning, which would presume truth as a "fact" and then seek its conditions, Deleuze holds that philosophy must adopt a method of genesis: truth must be seen to be a matter of production within sense (method of genesis) rather than adequation to a state of affairs (method of conditioning).

How then does this secondary organization of language (sense and non-sense) function with regard to the dynamic genesis of language? According to Deleuze, sense can be said to function simultaneously on two quite different registers. On the one hand, sense is what has been called the "expression" of a proposition, something that is irreducible to the other three dimensions of the proposition. In Frege's famous example, "Venus is the morning star" and "Venus is the evening star" are both true and both refer to the same state of affairs, yet they have different senses. Similarly, I can attribute the proper name "Battle of Waterloo" to a particular state of affairs, even though the battle itself exists nowhere but in my proposition. What we find in the state of affairs are bodies mixing with one another-spears stabbing flesh, bullets flying through the air, cannons firing, bodies being ripped apart-and the battle itself is simply the effect of the intermixing of these bodies. The battle itself exists nowhere except in my proposition, which attributes the name "Battle of Waterloo" to this particular state of affairs, this particular mixture of bodies. Deleuze is not referring here to a nominalism of universals, but rather to the singularity of proper names. Put differently, the Battle of Waterloo itself does not "exist" per se, but is something that merely "insists" or "subsists" in my proposition. One of the fundamental theses of Logic of Sense is that sense is to propositions what attributes like "Waterloo" are to states of affairs: they subsist or insist at their 
surface, they lie at the surface or borderline between propositions and states of affairs. Yet this first aspect of sense is only one aspect of Deleuze's book, and not even the most important one, although it is perhaps the one most frequently commented on. For, on the other hand, the second aspect concerns sense as the element of the genesis of propositions, and no longer simply the effect of propositions. Indeed, the complex relation between these two aspects of sense is the primary problem Deleuze tries to address in the book. How then does sense function as an element of genesis?

An infant is born into what Deleuze calls the primary order of language: noise, the primary affects (and sounds) of the body, with all its intensive variations. Simultaneously, in the midst of this primary order, the infant hears the Voice on High, that is, the voices of those speaking an already constituted language (Freud himself stressed the acoustic origins of the superego.) The problem of the dynamic genesis concerns the means by which the infant moves from the primary order of the body to the tertiary arrangement of language. Deleuze's claim is that this movement can be effectuated only by passing through the secondary organization of sense. It is obvious that for the infant the Voice on High already has all the dimensions of the "tertiary organization" of language, which pre-exists the life of the infant: it manifests the emotional variations of the speaker (the voice that loves and reassures, attacks and scolds, withdraws and keeps silent, complains about being wounded), it denotes states of affairs in the world, including good objects (breast) and introjected objects (food); and it signifies something, namely, all the classes and concepts that structure this domain of the Voice that pre-exists the infant. Yet the infant itself does not know what the Voice is denoting, manifesting, or signifying. For the child, the Voice "has the dimensions of language without having its condition; it awaits the event that will make it a language. It is no longer a noise, but is not yet language" (LS, 194). In other words, the Voice does not yet have a sense. Whereas the Noise of the depths is an infra-sense, an under-sense, an Untersinn, the Voice from the heights is a pre-sense; it still awaits the "event" that functions the genetic element of language itself.

But as Deleuze notes, this is not simply an experience of infants. The passage from noise to voice is re-lived when the sounds reaching sleeping people are organized into the voice ready to wake them. More obviously, we experience it when we encounter someone speaking a foreign language. The Greeks called non-Greeks "barbarians" (barbaros) because when they heard foreigners speak, all they heard were nonsensical syllables ("bar bar"). They heard the Voice, and they could 
see that it "made sense," that it had a sense, but they lacked access to the sense of the foreign language. Similarly, Americans tend to caricature the sound of French as extremely vowel-y, just as the French tend to characterize American speech in term of a hot potato in one's mouth, since most American vowel sounds are diphthongs.

Yet how does one gain access to this domain of sense? For the infant to accede to the tertiary arrangement of language (the Voice), it must pass through the secondary organization of language, which is the construction of the surface dimension of sense, entailing a certain period of apprenticeship on the child's part. From the continuous flow of the Voice which comes from above, the child will be begin to cut out, to extract, elements of different orders, to free them up in order to give them a function that nonetheless remains "pre-linguistic" (LS, 230). This is an early formulation of the theory of flows that Deleuze will develop in AntiOedipus. the voice is a flow from which elements, which are purely nonsignifying, are extracted and recombined. The first words of the infant are not formed linguistic units, but merely formative elements: phonemes, morphemes, semantemes.

In Deleuze's analysis, the construction of the surface organization of sense can be distinguished into at least three moments, which are defined by three types of series or syntheses (the connective, conjunctive, and disjunctive synthesis). In the first moment (connection), the child extracts pure phonemes from the current of the Voice, and connects them together in what linguists call "a concatenation of successive entities" (ma ma, da da, bay bee, etc.), which can then enter into more complex relations, or even an alignment of clusters (LS, 231). In the second moment (conjunction), there is the construction of esoteric words out of these phonemes, a formation that is brought about not by a simple addition of preceding phonemes but rather through the integration of the phonemes into convergent and continous series ("Your royal highness" is contracted into "y'reince"). In the third moment (disjunction), the child starts making these esoteric words enter into relation with other divergent and independent series. Yet even here the elements (singularities) are not yet organized into formed linguistic units that would be able to denote things, manifest persons, and signify concepts. Taken together, these three syntheses constitute the production of the surface of sense out of the Voice. If the first moment of the dynamic genesis is the movement from Noise to the Voice, the second moment is the movement from the Voice to Speech. This is the fundamental operation of the dynamic genesis, at least with regard to language: the extrication of pure phonemes-which are themselves expressed in differential relations, such as bat/cat-from the flow of the Voice. "If the 
child comes to a pre-existing language which it cannot understand," Deleuze writes, "perhaps conversely, it grasps that which we no longer know how to grasp in our own language, namely, the phonemic relations, the differential relations of phonemes" (LS, 230). Deleuze elsewhere makes a similar point with regard to the biological domain: "there are 'things' that only an embryo can do, movements that it alone can undertake or even withstand"-movements of folding and migration, for instance, that would tear an adult organism apart (DR, 215). The implication is the same in both domains: we are led astray in our analyses if we focus on fully formed individuals (in biology) or fully formed languages (in linguistics).

What then, within the dynamic genesis, is required in order for one to move from the primary order of noise to the tertiary arrangement of language? Deleuze's response is that the genetic condition of language is what he calls the "pure event," which is nothing other than the secondary organization of sense itself, or what Deleuze calls "the transcendental field." The concept of a transcendental field was first proposed by Husserl in his own writings on the status of sense. "Phenomenology, alone of all philosophies, talks about a transcendental field," Merleau-Ponty would later write in Phenomenology of Perception. "The process of making explicit ... is put into operation on the 'livedthrough' world itself, thus revealing, prior to the phenomenal field, the transcendental field. ${ }^{\prime \prime 9}$ The Logic of Sense has close affinities with the Phenomenology of Perception, except that Deleuze is attempting to isolate the field of sense rather than the field of perception. Deleuze, however, would critique the Husserlian conception of the transcendental field of sense-which is inscribed with "centers of individuation and individual systems, monads and points of view, and Selves in the manner of Leibniz" (LS, 99)-and instead follow Sartre's call for an impersonal transcendental field. ${ }^{10}$ Difference and Repetition (1968) and Logic of Sense (1969) are the primary works in which Deleuze attempts to explore and define the nature of this transcendental field. "The idea of singularities ... which are impersonal and pre-individual," he writes in Logic of Sense, "must now serve as our hypothesis for the determination of this domain and its genetic power" (LS, 99). Indeed, one could list an entire open-ended series of empirco-transcendental concepts that Deleuze develops to define the transcendental field: determinable elements, differential relations, singularities, convergent and divergent series with their differing syntheses (connective, conjunctive, disjunctive), the dark precursor, virtuality/actuality, differentiation/differenciation, multiplicity, indiscernibility, and so on. In this regard, the Logic of Sense is an exploration of only one aspect of the transcendental field, albeit an 
important one: "The surface is the transcendental field itself, the locus of sense and expression" (LS, 125).

The dynamic genesis thus finds its real condition in what Deleuze calls the static genesis, which resolves what Deleuze considers to be one of the fundamental problems of the logic of sense: "How can we maintain both that sense produces even the states of affairs in which it is embodied, and that it is itself produced by these states of affairs or the actions and passions of bodies?" (LS, 124). One the one hand, the question of the dynamic genesis concerns the means by which sense is produced from the depths of bodies and their states of affairs, i.e., sense is the means through which sounds are separated from bodies and organized into propositions (the expressive function); on the other hand, it is only through sense itself that states of affairs are constituted and attributed to bodies (e.g., the battle of Waterloo). Although Žižek sees these two conceptions of sense as "fundamentally incompatible," entire goal of the Logic of Sense is to elucidate the exact nature of their relation and their ultimate compatibility.

Sense is what separates sounds from bodies and organizes them into propositions, freeing them for the expressive function. "In the surface organization which we called secondary, physical bodies and sonorous words are separated and articulated at once by an incorporeal frontier. This frontier is sense, representing, on one side, the pure 'expressed' of words, and on the other, the logical attribute of bodies" (LS, 91). The organization of sense constitutes the transcendental field. In describing his project, Deleuze writes, "We seek to determine an impersonal and pre-individual transcendental field, which does not resemble the corresponding empirical fields [already constituted languages, or the tertiary order of language], but which nevertheless is not confused with an undifferentiated depth [the primary order of noise]. ${ }^{12}$ Sense lies at the logical genesis of the three dimensions of the proposition (denotation, manifestation, signification), but also at the ontological dimensions of the three relata (the denoted, the manifested, the signified). Sense forms a boundary or frontier between words and things that allows the two to relate to each other without reducing this relation to one of isomorphism or representation. Sense is, as it were, the a priori structure that conditions the dynamic genesis.

What then accounts for the shift in Deleuze's thinking between Logic of Sense and Anti-Oedipus? Why was Deleuze compelled to move from the surface-depth problem in Logic of Sense to the problem of the body without organs in Anti-Oedipus? The issue, it seems to me, revolves around the question of the mode of access we have (or do not have) to the primary order of language (noise). The implicit presupposition of 
Logic of Sense seems to be that we do not have access to the primary order, since this is precisely the domain of language that belongs to the mad.

Nothing makes this clearer than the profound thirteenth series of Logic of Sense ("Of the Schizophrenic and the Little Girl"), which compares the uses of language found in Lewis Carroll and Antonin Artaud respectively, each of whom exemplifies a very different type of non-sense. The first type of nonsense, found in Lewis Carroll, operates entirely within the secondary organization of sense. Carroll's technique is to take the already given formative elements of language (sense) and to establish new syntheses between them. The work "snark," for instance (in "The Hunting of the Snark"), is formed through a conjunctive synthesis of "snake" and "shark." Carroll's poem "Jabberwocky" begins with a series of such portmanteau words: "Twas brillig, and the slithey toves did gyre and gimble in the wabe, all mimsy were the borogroves, and the mome raths outgrabe." To which Alice responds, "Somehow it seemed to fill my head with ideas-only I don't exactly know what they are!"13 The poem seems to make "sense" to Alice because Carroll combines the elements of language in a way that still retains their sense, even though they are made to enter into a new synthesis. The term "slithey" is a synthesis of "slimy" and "lithe," and thus seems to have a sense, even though it is a nonsensical combination of elements.

But Deleuze also identifies a second, and more profound, type of nonsense, which is found in the poetry and writings of Antonin Artaud. Artaud considered Lewis Carroll's poems to be so much "pigshit," since Carroll was content to remain at the surface, making poems out of a little combinatorial game (snark = snake + shark). But that kind of nonsense is nothing-absolutely nothing-compared to the nonsense of the body, with its pure intensities and noises, which Artaud expressed in his crissouffles ("scream-breaths") "in which all literal syllabic, and phonetic values have been replaced by values that are exclusively tonic" (LS, 88)-and which are tied, moreover, to a profound pathology, an extraordinary lived experience. In a sense, Artaud follows the reverse path of the infant (though "regression" is hardly an appropriate concept for this process): the infant starts in the primary order of the body, and attains the tertiary arrangement of language by passing through, or constructing, the secondary organization of sense. But Artaud's schizophrenic pathology took him in the opposite direction. The tertiary arrangement of language (the proposition) is "grounded" in the "secondary organization" of sense (which is what Carroll plays with); and yet, following what Deleuze sometimes calls the "bend" in sufficient reason, the dimension of sense itself threatens to collapse into the ungrounded primary order of 
noise (Artaud). ${ }^{14}$ This is why Deleuze insists that "we would not give a single page of Artaud for all of Carroll" (LS, 93).

We are all aware of the fundamental fragility of this domain of sense and the fact that it can break down at any moment. If I were reading this paper to you, speaking in propositions, you would comprehend me because those propositions are sustained by the element of sense. Sense is the surface, the boundary, the frontier that exists between, on the one hand, the noises of my body (creaking joints and cracking knuckles, rumbling stomachs, clearing throats, etc.) and, on the other hand, the expressive sense that those noises take on in language, such that the noises coming out of my mouth participate fully in the linguistic world we all share, this tertiary arrangement of language. As Merleau-Ponty showed, the same is true for the entirety of my body, which is "expressive" through and through, having a sense in every one of its gestures. ${ }^{15}$

Indeed, does not Artaud's greatness, and his great pathos, lie in the fact that to some degree he was able to speak and write out of the depths of the primary order of the body? Nietzsche, for his part, seemed unable to do so, and lapsed into silence. Yet is Nietzsche's or Artaud's experience any different from our own? In a sense, yes, absolutely yes, since both Artaud and Nietzsche suffered a profound pathology most of us will never have to confront. But in another sense, no, things are not so different, since stumbling over a single word (parapraxes) would be enough to reveal the fragility of the sense that sustains what I am saying, the chaos that constantly threatens to bubble up and subsume everything, making us fall into "the undifferentiated abyss of a groundlessness which only permits the pulsation of a monstrous body" (LS, 120).

A revealing passage in Logic of Sense reveals Deleuze's hesitations about remaining at the surface, while remaining fully aware of the dangers of plunging into the depths-the depths into which Nietzsche himself "perished in his own manner" (LS, 108). Deleuze muses aloud about the situation of a philosopher like himself, writing on Artaud's schizophrenia, Nietzsche's collapse, Hölderlin's madness, Woolf's suicide, Fitzgerald's breakdown, Lowry's alcoholism, Bousquet's wound-all the while remaining on the surface, dipping his toes in the water, but not diving into the depths himself.

All these questions point to the ridiculousness of the thinker.... Are we to speak always about Bousquet's wound, about Fitzgerald and Lowry's alcoholism, Nietzsche and Artaud's madness while remaining on the shore? Are we to become the professionals who 
give talks on these topics? Are we to take up collections and create special journal issues? Or should we go a short way further to see for ourselves, to be a little alcoholic, a little mad, a little suicidal, a little of guerilla-just enough to extend the crack, but not enough to deepen it irremediably? Wherever we turn, everything seems dismal. Indeed, how are we to stay at the surface without staying on the shore? (LS 157-8).

In Anti-Oedipus, one might say, Deleuze took the plunge and dove into the depths. This is what separates Anti-Oedipus from the Logic of Sense. Anti-Oedipus explicitly takes the most extreme form of psychosis - schizophrenia-as its model for the unconscious, and it unhesitatingly attempts to write about the "depths" in a straightforward manner. In this, Deleuze seemed to have taken a cue from Lacan, who had insisted that the unconscious, or the Real, is revealed in its purest and least mediated form in psychosis, rather than in neurosis or perversion (neurosis, perversion, and psychosis being the three main categories in Lacan's diagnostic schema). Deleuze seems to have seen both Logic of Sense and Masochism: Coldness and Cruelty as somewhat timid books, approaching the question of the unconscious through still safe models drawn from perversion-the pervert having achieved a "mastery of surfaces. ${ }^{\prime \prime 16}$ Lacan himself, however, never used psychosis directly as a model for the unconscious. Psychotics resist entry into the Symbolic (foreclosure) because they mistake words for things; and they resist therapeutization because they have a libido that is too liquid or viscous. The dimension of the Real can at best only appear as a "gap" or "rupture" in the Symbolic. But rather than seeing foreclosure as a resistance of the ego, Deleuze sees it as the intensive outcry of what he calls "desiring-production" $(\mathrm{AO}, 67)$. Indeed, Deleuze's term for the Real is "schizophrenia as a pure process" (which must be distinguished from the schizophrenic as a clinical entity), and it is with this concept that Deleuze can be seen to have taken Lacan's thought to its limit and conclusion. "It is this entire reverse side of the [symbolic] structure that Lacan discovers ... schizophrenizing the analytic field, instead of oedipalizing the psychotic field" (AO, 309).

Hence, following directions hinted at by Lacan himself, Anti-Oedipus attempts to use the model of schizophrenia to describe the Real in all its positivity: differential partial objects or intensities that enter into indirect syntheses; pure positive multiplicities where everything is possible (transverse connections, polyvocal conjunctions, included disjunctions); signs of desire that compose a signifying chain, but which are themselves non-signifying, and so on (AO, 309). The domain of the Real is a 
"sub-representative field," but Deleuze does not hesitate to claim that "we have the means to penetrate the sub-representational."17 Some of Deleuze's most insightful texts on schizophrenics-such as "Louis Wolfson; or, The Procedure"-are those that analyze the specifically schizophrenic uses of language, which push language to its limit and undo its significations and designations. ${ }^{18}$ Deleuze suggests that the usual negative diagnostic criteria that have been proposed for schizophreniadissociation, detachment from reality, autism-are above all useful terms for not listening to schizophrenics. But in the end, this problem is not specific to schizophrenics: "we are all libidos that are too viscous and too fluid ..." (AO, 67; see 312$)$.

Whereas Logic of Sense was content to remain at the surface of sense (Lewis Carroll), Anti-Oedipus can be said to have plunged into the depth of bodies (Artaud). Why, then, does Deleuze no longer speak of the "depths" in Anti-Oedipus? At the very least, the concept of depth has relevance only from the viewpoint of a theory of surfaces; outside of that context, the notion of depth loses its relevance. Once Deleuze ensconces himself in the depths, so to speak, he requires a new conceptual apparatus. This is why in Anti-Oedipus the surface-depth problem of Logic of Sense is replaced with the problem of the body without organs, and the flows that traverse it. The concept of the "body without organs," which Deleuze derives from Artaud, had already appeared in Logic of Sense, but only as a means of describing the largely undifferentiated status of the depths of bodies-"an organism without parts which operates entirely by insufflation, respiration, evaporation, and fluid transmission" (LS, 88). In the depth of bodies, the possible uses of language are altered accordingly: "In this primary order of schizophrenia, the only duality is that between the actions and passions of bodies.... Here everything happens, acts, and is acted upon beneath sense and far from the surface-sub-sense, a-sense, Untersinn.... The word becomes the action of a body without parts, instead of being the passion of a fragmented organism.... There is no longer anything to prevent propositions from falling back onto bodies and from mingling their sonorous elements with the body's olfactory, gustatory, or digestive affects" (LS, 89-91). In the Logic of Sense, in other words, the transcendental field is the surface of sense itself, and the depths of bodies are a largely undifferentiated abyss into which one falls once the surface gives way. Although Artaud may have managed to give us a glimpse into the depths, he is the great exception: "Artaud is alone in having been an absolute depth in literature, and in having discovered a vital body and the prodigious language of this body. As he says, he discovered them through suffering. He explored the infra-sense, which is still unknown today. ${ }^{\prime 19}$ 
Anti-Oedipus attempts to explore the nature of this still unknown dimension of infra-sense; the transcendental field is pushed into the depths. If Deleuze abandons the surface-depth terminology it is no doubt because the notion of depth carries a somewhat negative connotation, as an undifferentiated groundlessness in relation to the constituted surface dimension of sense. Anti-Oedipus instead focuses on the specific element of depth that Artaud had discovered and named: the body without organs. In Anti-Oedipus, however, the body without organs is no longer linked with the depths, but rather is constituted by and constitutes its own transcendental field, which Deleuze characterizes in terms of the logic of the passive syntheses. Summarizing briefly, one could say that Deleuze assigns three fundamental components to the concept of the body without organs:

1. Organs-parts. Schizophrenics experience their organs in a nonorganic manner, that is, as elements or singularities that are connected to other elements in the complex functioning of a "machinic assemblage" (connective synthesis). In The Empty Fortress, for example, Bruno Bettelheim presents a portrait of little Joey, a kind of "child-machine" who could live, eat, defecate, breathe, and sleep only by plugging himself into motors, carburetors, steering wheels, lamps, and real or imaginary circuits. "He had to establish these imaginary electric circuits [raccordements] before he could eat, for only the current could make his digestive tract work. He executed this ritual with such dexterity that we had to double check to make sure he had neither cord nor socket." ${ }^{\prime 20}$

2. The Body Without Organs. But the breakdowns in the functioning of these organ-machines reveals a second theme: that of the body without organs as such, a non-productive surface upon which the an-organic functioning of the organs is stopped dead in a kind of catatonic stupor (disjunctive synthesis). In this sense, the body without organs is a model of death (the death instinct), albeit a death that is coextensive with life. Authors of horror stories, like Edgar Allen Poe, know this well, when they appeal to the terror, not of the organic corpse, but of the catatonic schizophrenic; the organism remains intact, with its vacant gaze and rigid postures, but the vital intensity of the body has been suspended, frozen, blocked.

3. Intensities. These two poles-the vital an-organic functioning of the organs and their frozen catatonic stasis, with all the variations of attraction and repulsion that exist between them - can be said to translate the entire anguish of the schizophrenic. These two poles are never separate from each other but generate between them various forms in which sometimes repulsion and sometimes attraction dominates: the paranoid form of schizophrenia (repulsion) and its miraculating or fan- 
tastic form (attraction). This is the third theme of schizophrenia: the theme of intensive variation (conjunctive synthesis). Schizophrenics tend to experience these oscillating intensities (manic rises in intensity, depressive falls in intensity) in an almost pure state. Beneath the hallucinations of the senses ("I see," "I hear") and the deliriums of thought ("I think"), there is something more profound, a feeling of intensity, that is, a becoming or a transition ("I feel"). A gradient is crossed, a threshold is surpassed or retreated from, a migration is brought about: "I feel that I am becoming woman," "I feel that I am becoming god," "I feel that I am becoming pure matter."

The innovation of Anti-Oedipus, beyond Logic of Sense, is to have penetrated into this sub-representative, schizophrenic domain of the body without organs and made use of it as the model for the unconscious itself. The analysis of this unconscious will entail a corresponding practice that Deleuze and Guattari will call "schizoanalysis." In developing his model of the body without organs, Deleuze admitted his debt to the work of Pierre Klossowski, notably the latter's Nietzsche and the Vicious Circle. Klossowski showed how we get a glimpse into Nietzsche's delirium in the letters and postcards he wrote before his collapse. In them, language took on a purely intensive use, insofar as it directly expressed the "primary order" of Nietzsche's body and its impulsive states. In Nietzsche's last writings, each of these states received its own proper name-some of which designated Nietzsche's "attractive" allies, or manic rises in intensity (Prado, Lesseps, Chambige, "honest criminals," Dionysus), while others designated his "repulsive" enemies, or depressive falls in intensity (Caiaphus, William, Bismark, the "antisemites," the Crucified)-a chaos of pure oscillations ultimately invested by "all the names of history. ${ }^{11}$ Yet was it not this very experience that Nietzsche confronted throughout all his writings, long before his breakdown?22 In any case, in Anti-Oedipus, Artaud no longer appears as the exception, the one who was able to speak from the "depths," and Deleuze is able to appeal to a long list of writers and thinkers who, as Klossowski shows, pushed the use of language to its intensive limits.

With this reading of Deleuze's own movement from Logic of Sense to Anti-Oedipus in hand, it should perhaps be clear why a Lacanian like Žižek would almost inevitably have to characterize Anti-Oedipus as Deleuze's worst book, and as a betrayal of Lacan. The issue revolves around the status of what Lacan called the Real. For an "orthodox" Lacanian, the Real is the name for a "gap" in the Symbolic, a moment of radical negativity that can never be approached in itself, but can only be discerned in its effects. Although Lacan himself insisted that psychosis provides the most direct access to the unconscious, the access psycho- 
tics have to the symbolic is necessarily "foreclosed." It is this orthodox interpretation of the Real that Deleuze and Guattari contest in AntiOedipus. The Real is indeed the internal limit to any process of symbolization, but Deleuze insists that Lacan was never content to describe the Real, negatively, as a resistant kernel within the symbolic process upon whose internalized exclusion the symbolic is constituted (negation or exclusion as constitutive). Rather, Lacan was pushing psychoanalysis to "the point of its self critique," where the Real would be able to appear in all its positivity: "the point where the structure, beyond the images that fill it [fantasies] and the Symbolic that conditions it within representation, reveals its reverse side as a positive principle of nonconsistency that dissolves it." ${ }^{\prime 23}$ What Lacan discovered (and what psychosis makes manifest most directly) is the reverse side of the symbolic structure, and Deleuze can say that he was simply following directions indicated by Lacan himself when, in Anti-Oedipus, he and Guattari attempted to describe the Real in all its positivity: differential partial objects or intensities that enter into indirect syntheses; pure positive multiplicities where everything is possible (transverse connections, polyvocal conjunctions, included disjunctions); signs of desire that compose a signifying chain, but which are themselves non-signifying, and so on. The fundamental question no longer concerns the means by which a transcendent "gap" is constituted within the Symbolic, but the immanent means by which the Real is betrayed and converted into a symbolizing structure. Put simply, one could say that psychoanalysis begins with the symbolic and seeks out the gaps that mark the irruption of an "impossible" Real, whereas schizoanalysis starts with the Real as the immanent process of desire, and seeks to mark both the mechanisms by which the process is interrupted (reterritorializations) and the conditions under which it can be continued and transformed (becomings, intensities). It is perhaps in this sense that, as Deleuze himself said in the Abécédaire interviews of 1998-1999, Anti-Oedipus is "a book still to be discovered," above all by readers of Lacan. ${ }^{24}$

dsmith@sla.purdue.edu

\section{Notes}

1. Slavoj Žižek, Organs Without Bodies: On Deleuze and Consequences (New York: Routledge, 2004), 21. See Gilles Deleuze, Logic of Sense [1969], ed. Constantin Boundas, trans. Mark Lester and Charles Stivale (New York: Columbia University Press, 1988), hereafter cited as LS; and Anti-Oedipus: Capitalism and Schizophrenia [1972], trans. Robert Hurley, 
Mark Seem, and Helen Lane (Minneapolis: University of Minnesota Press, 1983). Hereafter cited as AO.

2. Deleuze, LS, 124. See also LS, 96: "How are we to reconcile these two contradictory aspects [of sense]? On one hand, we have impassibility in relation to states of affairs and neutrality in relation to propositions; on the other hand, we have the power of genesis in relation to propositions and in relation to states of affairs themselves."

3. Žižek, Organs Without Bodies, 20.

4. In short, Žižek is suggesting that Logic of Sense anticipates Badiou's distinction between Being and Event: Being is the domain of corporeal causality, whereas the event corresponds to the domain of incorporeal effects, which introduces "a gap in corporeal causality," "an irreducible crack in the edifice of Being" (Organs Without Bodies, 27, 41).

5. See Žižek, Organs Without Bodies, 21.

6. Deleuze, Desert Islands and Other Texts, 1953-1974, ed. David Lapoujade, trans. Michael Taormina (New York: Semiotext[e], 2004), 261. See the discussion following "Nomad Thought."

7. Daniel N. Stern, Diary of a Baby (New York: Basic Books, 1990), 14: "a sudden increase in interest; a rising, then a falling wave of hunger pain; an ebbing of pleasure."

8. Deleuze, Difference and Repetition, trans. Paul Patton (New York: Columbia University Press, 1994). 154. Hereafter cited as DR.

9. Maurice Merleau-Ponty, Phenomenology of Perception, trans. Colin Smith (New York: Routledge, 1962; rev. ed. 2003), 71, 69. In Logic of Sense, Deleuze criticizes Husserl for defining the transcendental field in terms of "centers of individuation and individual systems, monads and points of view, and Selves in the manner of Leibniz" (LS, 99).

10. See LS, 98-9 and 343-4, as well as Jean-Paul Sartre, The Transcendence of the Ego: An Existential Theory of Consciousness [1937], trans. Forrest Williams and Robert Kirkpatrick (New York: Farrar, Straus, and Giroux, 1991). 


\section{1. Žižek, Organs without Bodies, 20.}

12. Deleuze, LS, 102. See also Merleau-Ponty, Phenomenology of Perception: "Phenomenology, alone of all philosophies, talks about a transcendental field.... The process of making explicit ... is put into operation upon the 'lived-through' world itself, thus revealing, prior to the phenomenal field, the transcendental field" $(71,69)$.

13. Lewis Carroll, Through the Looking-Glass, in The Complete Works of Lewis Carroll (New York: Modern Library, 1979), 153-5.

14. On the relation between these three orders of language, see LS, 120.

15. See Merleau-Ponty, Phenomenology of Perception.

16. Deleuze, LS, 92. See Deleuze, Masochism: Coldness and Cruelty, trans. Jean McNeil (New York: Zone Books, 1991).

17. Deleuze, "The Method of Dramatization," in Desert Islands, 115.

18. See Deleuze, "Louis Wolfson; or, The Procedure," in Essays Critical and Clinical, trans. Daniel W. Smith and Michael A. Greco (Minneapolis: University of Minnesota Press, 1997). See also AO, 310: "Elisabeth Roudinesco has clearly seen that, in Lacan, the hypothesis of an unconsciousas-language does not closet the unconscious in a linguistic structure, but leads linguistics to the point of its auto-critique, by showing how the structural organization of signifiers still depends on a despotic Great Signifier acting as an archaism."

19. Deleuze, LS, 93. Emphasis added.

20. Bruno Bettelheim, The Empty Fortress: Infantile Autism and the Birth of the Self (New York: Free Press, 1972). See also AO, 37-8.

21. Pierre Klossowski, Nietzsche and the Vicious Circle, trans. Daniel W. Smith (Chicago: University of Chicago Press, 1997), especially chapter nine, "The Euphoria of Turin."

22. See, for instance, Nietzsche, Beyond Good and Evil, §296, pp. 426-7: "Alas, what are you after all, my written and painted thoughts! Alas, only Alas, always only what is on the verge of withering and losing its fragrance! Alas, always only storms that are passing, exhausted, and feelings that are 
autumnal and yellow! Alas, always only birds that grew weary of flying and flew astray and how can be caught by the hand-by our hand. We immortalize what cannot live and fly much longer-only weary and mellow things!"

23. Deleuze and Guattari, AO, 310, 311.

24. See Deleuze, "Abécédaire," "D as in Desire," available online in a summary by Charles J. Stivale at www.langlab.wayne.edu/CStivale/D-G/ ABCs.html. 